ISSN: 2675-7451

Vol. 02 - n 03 - ano 2021

Editora Acadêmica Periodicojs

\title{
PODER, HOMOSSEXUALIDADE E VELHICE: AS \\ TRANSGRESSÕES E SILENCIAMENTOS SOB A RE- \\ PRESENTAÇÃO DE ALVO DUMBLEDORE
}

\author{
POWER, HOMOSEXUALITY AND OLD AGE: \\ TRANSGRESSIONS AND SILENCES UNDER TAR- \\ GET DUMBLEDORE REPRESENTATION
}

\begin{abstract}
Gabriella Aguilar Cardozo ${ }^{1}$
Resumo: Compreender as nuan- gico, também se criticam os poces que permeiam personagens sicionamentos de J. K. Rowling da cultura popular em filmes e para lidar com a realidade de sua livros nos permite aprofundar criação. Intrínseco a essas quesdebates reais acerca de temáticas tões, é proposto um aprofundaque se afastam do status quo em mento de mentalidades ao se múltiplos níveis. Ao perceber no perceber as formas pelas quais a universo de Harry Potter problesociedade recebe a homossexuamatizações relevantes inerentes lidade na velhice.

a Alvo Dumbledore, é feita uma análise que circunscreve desde sua vida privada, aos seus cargos ocupacionais e posicionamentos Palavras-chave: Homossexualidade; Velhice; Dumbledore; Harry Potter; Pink Money.

políticos. Saindo no mundo má-
\end{abstract}

1 Licencianda de História pela Universidade Federal Rural do Rio de Janeiro.

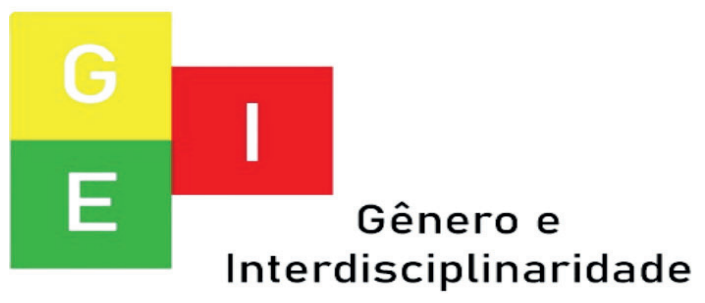


ISSN: 2675-7451

Vol. 02 - n 03 - ano 2021

Editora Acadêmica Periodicojs

Abstract: Understanding how nuances permeate popular culture characters in films and books allow us to deepen real debates about themes that depart from the status quo at multiple levels. When realizing relevant problems inherent to Albus Dumbledore in the Harry Potter's universe, an analysis is made that circumscribes from his private life, to his occupational functions and political positions. Coming out into the magical world, J. K. Rowling's positions to deal with the reality of his creation are also criticized. Intrinsic to these issues, a deepening of mentalities is proposed when perceiving the ways in which society receives homosexuality in old age.

Keywords: Homosexuality; Old age; Dumbledore; Harry Potter; Pink Money.

\section{Introdução}

O presente trabalho se valerá de uma perspectiva política que circunscreve o personagem Alvo Dumbledore, de criação da escritora J. K. Rowling nos campos literário e cinematográfico de Harry Potter. Aqui se concretizará o intento de compreender a forma como são concentradas em tal personagem características que se aproximam e se afastam, com vários aspectos do senso comum, sobre o que se espera de uma figura de poder. Delineando-se pelas esferas do profissional e do pessoal, Dumbledore irá de encontro com expectativas socialmente construídas acerca da masculinidade (OLIVEIRA, 2004) (REIS, 2012); além disso, se valerá da forma como o personagem é construído em contraste com a forma como este é representado, ou seja, há outra

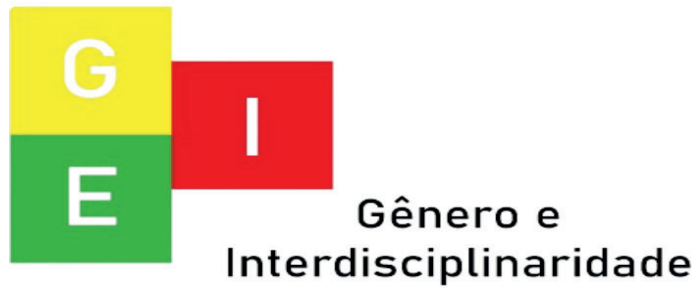


ISSN: 2675-7451

Vol. 02 - n 03 - ano 2021

Editora Acadêmica Periodicojs

paridade de confronto: no meio mágico de seu próprio universo e no meio cinematográfico, no que concerne à indústria do cinema e aceitação do público.

\section{ALVO PERCIVAL WULFRI- CO BRIAN DUMBLEDORE}

Alvo Dumbledore é diretor da escola de Magia e Bruxaria de Hogwarts - nomeadíssima escola inglesa que se dispõe a ensinar jovens bruxos a controlar suas inclinações às práticas mágicas. A personalidade deste personagem é reconhecida pela extrema erudição, respeito e força mágica por todo o mundo bruxo, mas principalmente, é caracterizada pela boa liderança, docilidade, compreensão e preocupação com causas minoritárias e de resistência em organizações extraoficiais para combater ameaças que são negadas pelo governo ou coniventes por este.

Trabalhando as características típicas de um bom líder masculinizado, enxergamos a reprodução arquetípica do homem branco enquanto forte, poderoso, sério e erudito; ao passo que, enquanto quebra de expectativas, temos um líder ao mesmo tempo que forte, também afetuoso, de idade para além do que é construído enquanto "velho sábio" e, além disso, homossexual, sem que sua força e capacidade para liderança sejam questionadas por qualquer um desses aspectos (ROWLING, 2012).

Por outra ótica, a respeito de seu lado pessoal, Dumbledore teve de enfrentar a morte dos pais, passando a gerir sua família enquanto irmão mais velho entre seus outros dois irmãos, sendo a mais nova uma menina com limitações cognitivas. A partir disso é possível se pensar a questão da

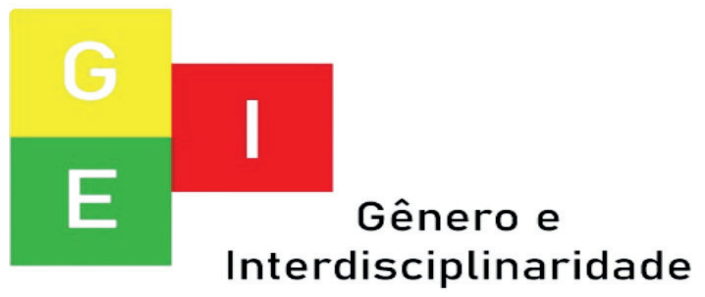


ISSN: $2675-7451$

Vol. 02 - n 03 - ano 2021

Editora Acadêmica Periodicojs

importância do irmão mais velho enquanto exemplo aos mais novos, principalmente entre meninos (WELZER-LANG, 2001). É interessante perceber o exemplo sob o qual cresceria seu irmão mais novo, pois, além de possuir uma imagem diferenciada no que diz respeito à masculinidade passível de afeto, há também o ponto de nosso personagem se impor contra as causas da pureza mágica sanguínea, fazendo com que, mais tarde, seu irmão também tomasse este partido.

De pouco adiantaria, porém, tais construções acerca de um personagem se este não adquirisse relevância na história principal a que se faz mover os livros e filmes de Harry Potter. Se faz notar, portanto, a centralidade que é conferida à Dumbledore: no que remete à sua importância para a narrativa, ele possui grande proximidade com o pro- tagonista, sendo um personagem de grande e ativa participação na história como seu mentor, conselheiro, guardião e, de certa forma, até mesmo figura paterna. De equivalente relevância, Dumbledore também é um grande bruxo em seu universo, pois além do sobredito, sua presença histórica é incontestável devido à sua atuação brava e grandiosa nas duas Grandes Guerras Bruxas, sendo por isso, considerado por muitos o maior bruxo de todos os tempos.

Isto posto, se tornam fundamentais inserções acerca da importância representativa concentrada neste personagem, e isto se fará em três esferas: o poderio mágico, o poderio intelectual e o poderio moral aliados à masculinidade. Em primeira instância, seu poderio mágico, além do colocado acerca de sua atuação nas guerras - que são conhecidas

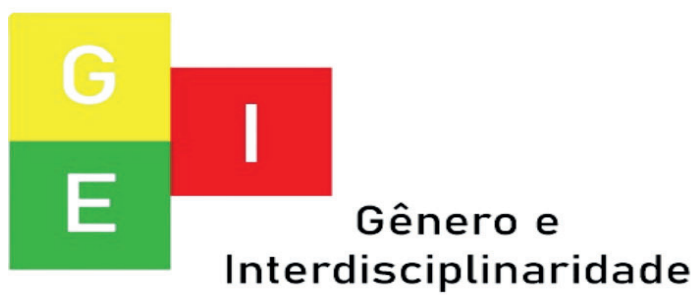


ISSN: 2675-7451

Vol. 02 - n 03 - ano 2021

Editora Acadêmica Periodicojs

apenas de forma secundária, uma vez que não mostradas nas obras

-, é mostrado seu triunfo sobre os dois maiores e mais fortes vilões deste universo; somando-se ao fato de, em consequência disto, possuir a varinha mágica mais forte e desejada do mundo, conferindo um prestígio inestimável em equivalência à grandiosidade do personagem (podemos inclusive fazer um exercício de analogia entre varinhas, seu formato fálico e sua centralidade para demonstração de poder e validação de sobrepujança social). No âmbito intelectual, seu reconhecimento também não é garantido de forma gratuita, pois, além de ter sido um aluno de destaque à sua época de estudante, também se mostrou um brilhante professor de transfiguração, ascendendo ao cargo de diretor. Ademais, possui grande aclamação sobre seus trabalhos como alquimista e legislador, tendo-lhe sido oferecido o mais alto cargo jurídico deste universo -Ministro da Magia -, recusado devido ao medo em retrospecto às atitudes tomadas em nome do poder.

Por fim, seu poderio moral (colocado desta forma por se acreditar na moral amplamente reconhecida enquanto capital de poder equivalente aos outros pontos trazidos), revelava o equilíbrio entre o respeito por humildade e o respeito por incisão, pois, principalmente pelo exemplo dos filmes segundo (A Câmara Secreta) e quinto (A Ordem da Fênix) desta saga, ao vermos Dumbledore agindo de forma séria e firme, revelando novamente que a figura masculinizada de poder, além de não precisar ser cruel e poder ser afetuosa, ainda pode agir de maneira incisiva e imponente. Outrossim, fica explícito o quanto seus inimigos

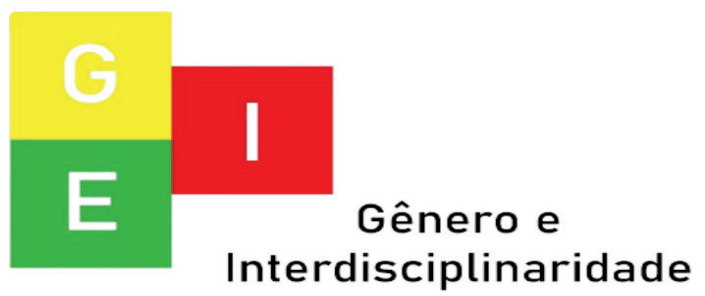


reconhecem a ameaça oferecida por ele, provando que o respeito não somente se dá por aqueles que o apreciam. Da mesma forma, em nenhum momento revelam-se situações homofóbicas, uma vez que o desprezo de seus inimigos se dá por contraposição ideológica devido à proteção dos grupos desmoralizados (ainda que sua homossexualidade não seja trazida de modo explícito, há um personagem específico trabalhado mais adiante que sabe de sua orientação e permanece desconsiderando-a para provocações e enfrentamento).

\section{FORA DO MUNDO MÁGICO}

Em meio a tantos aspectos positivos que tornam o personagem de grande contribuição representativa, como ao trazer novas formas de se reproduzir a masculinidade em posições de poder, e também por trabalhá-las com homossexuais as ocupando e sendo profundamente respeitados neste local; ainda rompem com estereótipos que associam homossexualidade à fragilidade (por serem extensões de uma "feminilização" do homem ao se afastar das categorias marcadoras da masculinidade) (GREEN, 2012), em contrapartida, há de se encontrar impecílios no meio cinematográfico. Estas dificultações foram percebidas em dois momentos por três frentes diferentes: a primeira, à época da manifestação de J. K. Rowling a respeito da sexualidade de Dumbledore e sobre como ele havia sido pensado sob esta ótica apesar de não ter sido anunciado enquanto tal; a segunda, sobre como parte da sociedade tratou esse assunto como desnecessário e forçoso; a terceira, mais recente, quando esta sexualidade, já

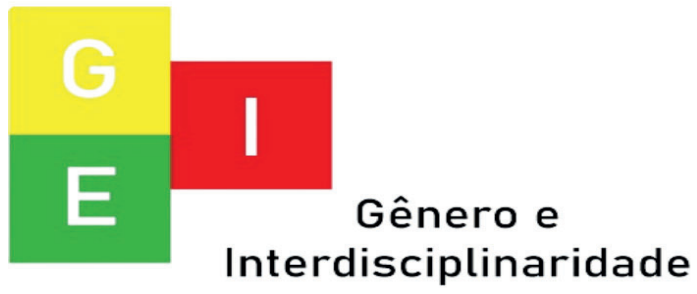


ISSN: 2675-7451

Vol. 02 - n 03 - ano 2021

Editora Acadêmica Periodicojs

assumida há alguns anos pela escritora, se faria retratar na nova saga sobre este mesmo universo literário, "Animais Fantásticos". No primeiro momento descrito, podemos inferir duas problemáticas: a primeira a respeito dos fãs do universo Harry Potter, pois nem todos estiveram abertos a essa possibilidade, uma vez que vivemos sob estigmas de uma heterossexualidade compulsória e, além disso, nem todos se encontram com disposição à diversidade sexual percebida, debatida e representada, configurando posturas homofóbicas e por vezes até agressivas à Rowling -e, por extensão, ofensivas ao público LGBTQI+ também. O segundo ponto a se enxergar um problema é no fato de a escritora não ter jamais feito menção a esta sexualidade de Dumbledore nos livros já publicados. Se por opção pessoal, medo de rejeição, falta de senti- mento de abertura para este debate ou apenas crítica subentendida ao pressuposto heteronormativo - já que também nunca fora dito que o personagem era heterossexual -, onde se quer chegar é: a falta de posicionamento limita a representatividade que se pretendia dar ao público que pertence a esta seção. Ademais, pode ser visto como atitude oportunista para ganhar audiência e foco midiático, uma vez que hoje existe um público interessado nessas temáticas (ainda que exista rejeição) que movimenta uma quantidade considerável de dinheiro, conhecido como pink money.

No momento seguinte, uma outra camada de rejeição é acrescida à sexualidade de Dumbledore; nesta chave perdem-se, inclusive, grupos de pessoas favoráveis - e até mesmo pertencentes - à causa LGBTQI+. Trata-se aqui da problemática que

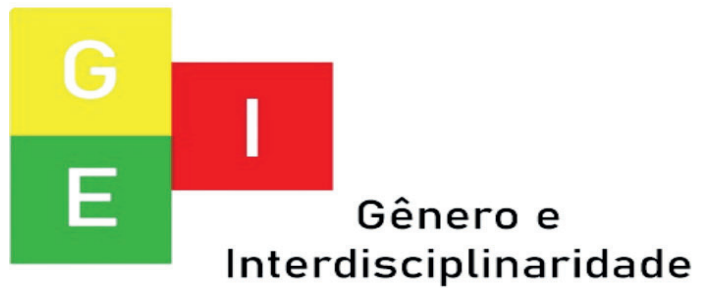


ISSN: $2675-7451$

Vol. 02 - n 03 - ano 2021

Editora Acadêmica Periodicojs

delineia o aspecto da idade somado ao desejo sexual, ou menos até, já que sequer é adquirido este recorte explicitamente. Agregando o critério interseccional, onde há de se incluir as zonas de interseção entre gênero, etnia, sexualidade e faixa etária, nota-se que os afastamentos deste personagem de uma comoção por parte do público, é sofrida por ser homossexual velho, mesmo que polido por se inserir como homem branco no debate.

Ainda assim, esse afastamento se dá devido ao olhar construído sobre pessoas velhas como impassíveis de novas relações e sentimentos afetivos, uma vez que a concepção do amor romântico e vida sexual é trabalhada em cima da imagem da juventude, como é colocado pelo autor Altair Pocahy ao parafrasear Le Breton: "a velhice desliza lentamente para fora do campo simbólico, ela se afasta dos valores da modernidade: a juventude, a sedução, a vitalidade, o trabalho, a performance de desempenho, a rapidez." (apud Le Breton, 2011:22). Desta forma, ergue-se esse recorte de pessoas sob argumentos que refletem a abjeção sofrida por idosos, não os vendo como ainda no direito de expressar desejo, e sim apenas como lócus de experiências já vividas e mais nada de novo a ser ainda experimentado (POCAHY, 2011).

Se levantará este debate rapidamente para que se compreenda esta forma de violência que é tão invisibilizada, independentemente do recorte sexual - mas se agravando a cada etapa de marginalização. É denunciado de maneira generalizada as formas de abjeção sofridas por pessoas velhas, pois, antes mesmo de se inferir o recorte dedicado, a sociedade voltou toda sua

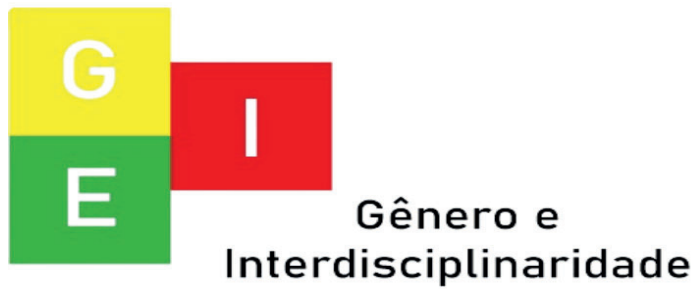


ISSN: 2675-7451

Vol. 02 - n 03 - ano 2021

Editora Acadêmica Periodicojs

mentalidade à juventude: desde a restrição às formas de lazer considerando não apenas acessibilidade, mas também noção da possibilidade participativa -, passando pela falta de inclusão ao se pensar mercado consumidor, até os níveis mais graves como o do imaginário sexual (POCAHY, 2011). Na cultura jovem não se possui a noção de ver idosos indo aos mesmos lugares de lazer que pessoas mais jovens, como cinemas ou shoppings, mas sim em bingos ou igrejas; não existem direcionamentos de marketing de consumo recreativo - como lojas de roupas ou eletrônicos para pessoas de idade avançada, apenas para remédios, artigos religiosos, planos de saúde e até funerários.

Mais distante ainda se encontra a possibilidade de refletir os idosos como passíveis de desejo e vida sexual, pois foi vendida a imagem do idoso assexuado, do fim da vida sexual ao se atingir determinada idade, e a vida representando uma corrida contra esse tempo. Aprofundando esta seção, ainda que se permita considerar a existência da vida sexual na velhice, são sempre consideradas como dentro de um casamento que existe provavelmente há mais 50 anos. Há quase uma impossibilidade em se transferir o campo das masculinidades do debate corriqueiro no campo do sexo extraconjugal da terceira idade e a impossibilidade em se pensar isso é ainda mais concreta quando se reflete sobre a homossexualidade. Por este motivo a homossexualidade idosa causa tamanho desconforto: pois temos de enfrentar o que nos conformamos a ignorar, e esse desconforto muitas vezes vem acompanhado de um sentimento de repulsa. À esta soma de invisibilização

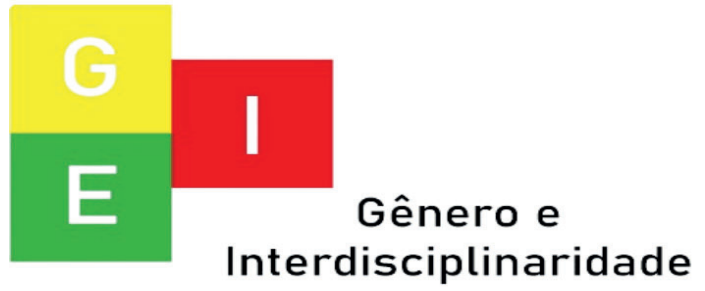


posta à margem com a repulsa pelo defronte do que "não devia existir", se caracteriza a abjeção, que, na opinião daquela que escreve, confere a maior ferida de violência simbólica, uma vez que sequer é considerada aquela existência, demonstrado por Crístian Paiva (PAIVA, 2009) como "uma posição de degradação, de aviltamento, de desvalorização do sujeito diante do laço social."

\section{GELLERT GRINDELWALD}

Ao se retomar o debate central deste levantamento, já no último momento, se faz perceber, de modo a quebrar expectativas, o silenciamento cinematográfico a respeito da sexualidade de Dumbledore. A primeira saga de filmes do universo do Universo Mágico se encerrou em 2012, já encontrando, JK, abertura para falar sobre homossexualidade na literatura. Entretanto, ao se iniciar outro arco deste universo, em 2015, quando a autora finalmente teria tempo de trabalhar este aspecto em seu personagem, foi dito que talvez este não seria abordado de maneira clara, mas implícita, oferecendo capital argumentativo para aqueles que classificaram sua primeira atitude como objetivo de ganhar pink money, uma vez que agora correria o risco de críticas negativas ao filme e perda da audiência mais conservadora. $\mathrm{O}$ que se torna relevante salientar é que a sexualidade de Dumbledore se faz relevante para o enredo principal dos novos filmes, quando outro personagem ganha enfoque narrativo. Todavia, torna-se relevante apenas enquanto homem branco homossexual, uma vez que por se passar em gerações anteriores, não pode ser inserido o recorte etário, e sendo con-

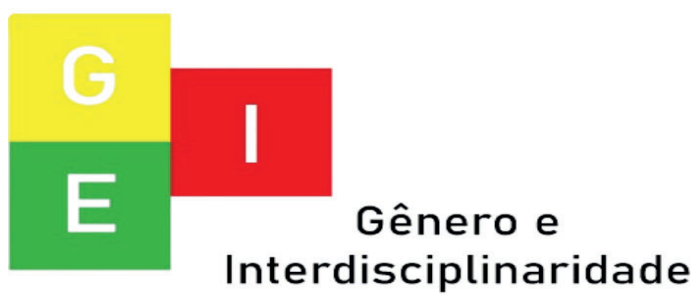


Vol. 02 - n 03 - ano 2021

Editora Acadêmica Periodicojs

venientemente mais aceito pelo público agora por ser passível de se imaginar como ser que possui desejos, posto que está inserido na faixa tomada pela sociedade como a sexualmente ativa, em contrassenso ao "velho bonzinho, assexuado [...] frequentemente significa a paralisação do seu desejo e dos poderes de seu corpo, como se este não importasse mais enquanto corpo sexual" (PAIVA, 2009).

Gellert Grindelwald seria o primeiro antagonista a surgir no Universo Mágico - cronologicamente - e sua motivação ideológica é a pureza sanguínea e o rompimento do segredo que divide os mundos bruxo e não-bruxo; uma guerra é desdobrada acerca dessas disputas. Todavia o que nos interessa para a temática do presente trabalho é o entendimento da dinâmica entre este e Dumbledore: sendo amigos des- de muito jovens e parceiros intelectuais, Dumbledore desenvolveu sentimentos por Grindelwald e este se aproveitou da condição de dependência emocional do primeiro para manipulá-lo a seguir suas ideologias. Dumbledore, depois de certo tempo, percebe os perigos e contrassensos do que defende seu amigo e, ao não conseguir fazer com que este mude de ideia, se afasta. $\mathrm{O}$ que não se podia teorizar eram as dimensões que a ideologia de Grindelwald tomaria e, ao se tornar uma real ameaça para a segurança do mundo bruxo e atentado à inúmeras vidas, se faz questionar por quê o bruxo mais poderoso daquele universo não estava a impedi-lo. São justamente os sentimentos de Dumbledore por Grindelwald que permitem que a guerra adquira grandes proporções, por este motivo este primeiro não conseguira agir contra ele.

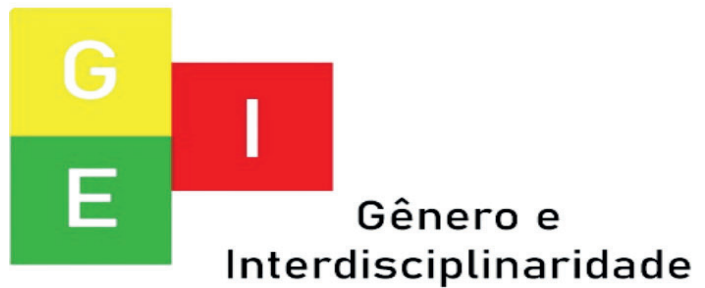


ISSN: 2675-7451

Vol. 02 - n 03 - ano 2021

Editora Acadêmica Periodicojs

Finalmente, o tão adiado enfrentamento ocorre e Grindelwald perde, sendo preso até sua morte. Contudo, ao não retratar isso nos filmes, tornar-se-ia incompleta a compreensão do porquê é tão dificultosa essa batalha, já que a ausência de uma problematização da representação da masculinidade, permite que se passe despercebido qualquer outra relação de tensão entre homens que não seja a de entraves agressivos ou de disputas por poder.

Uma breve chave argumentativa se faz bem colocada neste momento: acerca dos pressupostos heteronormativos que circundam Dumbledore, da mesma maneira se fez pensar o arquétipo de vilania em personagens literários. Esta história entre os personagens trazidos garante uma fenda interpretativa, pois, ainda que Grindelwald houvesse apenas manipulado Dumbledore, gostaria de propor uma menor especulação a ser feita: até que ponto seria apenas interesse coercitivo e a partir de que ponto seria possível que Grindelwald correspondesse? Ainda que não se façam importantes respostas a esses questionamentos, é a capacidade de se possibilitar em nosso imaginário a ideia de um vilão gay, rompendo, ao menos nesse aspecto, com os padrões socialmente engendrados de se relacionar da masculinidade heterossexual viril; em oposição à homossexualidade frágil, dócil e vulnerável, uma vez que ambos espectros são postos de modo hierarquizado socialmente, e, tratada esta última como negação parcial de uma masculinidade, por definição categórica binária, configuraria uma aproximação de aspectos da feminilidade, que, por sua vez, seria composta de tais elementos que deveriam ser

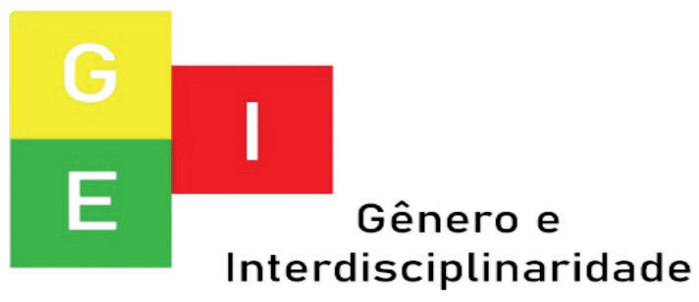


ISSN: 2675-7451

Vol. 02 - n 03 - ano 2021

Editora Acadêmica Periodicojs

evitados (GREEN, 2012).

\section{Considerações Finais}

Foram aqui levantadas, analisadas e criticadas diversas questões acerca da representatividade de Alvo Dumbledore. Construímos o contexto sobre o qual é gerida a história e relevância do personagem tanto em sua carreira profissional quanto familiar, perpassando as três esferas de análise (mundo literário, mundo cinematográfico de Harry Potter e mundo cinematográfico de Animais Fantásticos) ao demonstrar que espaçados por temporalidades diferentes -anos 90,2000 e 10 - foram tomadas posturas também diferentes não para sua criação, mas no modo em que, posteriormente, foram debatidas essas questões.

A seguir, passamos por seu aspecto transgressor às no- ções de masculinidade e poder, como rompimento com o caráter agressivo comumente atribuído a quem ocupa cargos administrativos de topo hierárquico. Posteriormente observou-se o par homossexualidade e poder, conferindo representatividade não apenas pela simples caracterização do personagem enquanto tal, mas por sua inteligência, moral e força, pois, mesmo não sendo clara sua orientação no universo, a confirmação por parte da autora nos faz rever as obras com esse olhar, garantindo àquele que se identifica como igual, a possibilidade de se ver retratado.

Mais adiante levantaram-se críticas a respeito de um suposto interesse em dimensionar a posteriori a homossexualidade de um personagem que já obtém sucesso como fórmula para se obter pink money, mas, em contrapartida, resguardar o

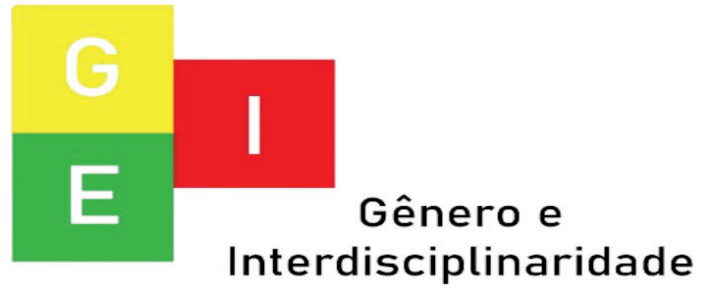


Vol. 02 - n 03 - ano 202

Editora Acadêmica Periodico.

potencial de visibilidade quando esta voltaria às telas de cinema. Também foram criticadas não apenas a homofobia de certos recortes do fandom como também um recorte ainda mais profundo ao tomarmos dimensão da gravidade do processo de abjeção sofrido por homossexuais velhos. Trabalhou-se com o silenciamento cinematográfico ao ignorar a relevância para o enredo de se trabalhar a homossexualidade deste personagem e, por fim, nos deparamos com pressupostos heteronormativos que delineiam também os vilões literários.

A partir do todo exposto, fica evidente - além do meu profundo afeto por este personagem e pela temática do presente estudo - o quanto se pode extrair por meio da politização de uma história literária. Devido a isso, se faz notar a importância de trabalhar esses recortes e não enxer- gar ficções como um todo-dado, de forma estática, pois sem este exercício para a criação de fendas interpretativas, não conseguiremos perceber as características de nossa própria sociedade ao analisar a maneira pela qual esta define o olhar a ser direcionado para determinado objeto. Finalmente, não apenas toda a saga de Harry Potter, mas também o Universo Mágico como um todo, traz diversos cenários e analogias políticas passíveis de interesse de análise.

\section{Referências Bibliográficas:}

GREEN, James. Quem é o macho que quer me matar? Homossexualidade masculina, masculinidade revolucionária e a luta armada brasileira dos anos 1960 e 1970. Revista Anistia Política e Justiça de Transição. Brasília: Ministério

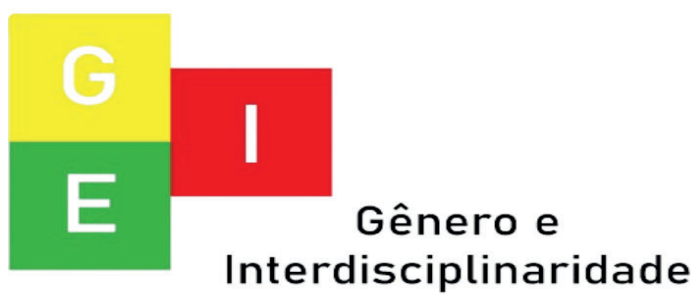


da Justiça, n. 8, p. 58-93, jul-dez. sidade Federal Do Rio Grande do 2012.

Sul, RS. p. 1-47.

J. K. Rowling (2012), “Alvo Dumbledore”, Blog Público. Consultado a 20.06.2019, em https://harrypotter.fandom.com/pt-br/wiki/ Alvo_Dumbledore

OLIVEIRA, Pedro Paulo. A construção social da masculinidade. Belo Horizonte: Editora UFMG; Rio de Janeiro: IUPEREJ, 2004, p. 141 - 191.

PAIVA, Crístian. Corpos/Seres que não importam? Sobre homossexuais velhos. Bagoas, n. 04, 2009, p. 191-208.

POCAHY, Fernando Altair. Entre vapores e dublagens: dissidências homo/eróticas nas tramas do envelhecimento. 2011. $167 \mathrm{f}$. Tese (Doutorado em Educação) Faculdade de Educação, Univer-
REIS, Ramon Pereira dos. "Eu tenho medo de ficar afeminado": performances e convenções corporais de gênero em espaços de sociabilidade homossexual. Rev. NUFFEM.v. 4, n. 1, jan.-junho, 73-87, 2012.

WELZER-LANG， Daniel. A construção do masculino: dominação das mulheres e homofobia. Revista Estudos Feministas. Rio de Janeiro: UFRJ, 2001, v. 9, n. 2, p. $460-482$.

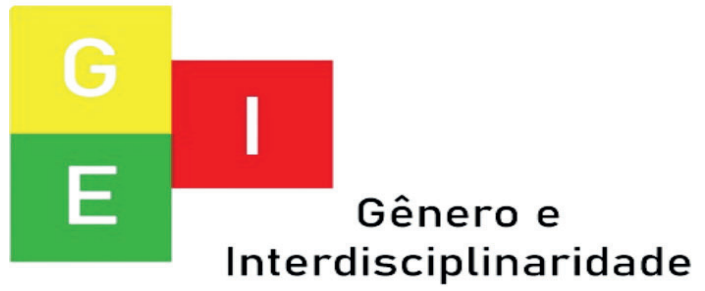

